well-staffed consumer oriented organisation like MIND in the UK and further support from existing voluntary organisations.

Finally, Japan needs to have more international support on these issues. Without this, true reform will never be achieved.

\section{Acknowledgements}

I would like to thank Ms Joan Shenton for her linguistic advice which was extremely helpful.

I also greatly appreciate the kind understanding of $\mathrm{Mr}$ Niall MacDermot, Secretary General of the ICJ; Dr N. W. de Smit, Chairman of International Seminar on Mental Health Legislation; and Dr Robert Myers, then President of the ANZAPPL for their kind understanding in my using many parts of my previous lectures: Development in Mental Health Legislation in Japan, which was published by the Faculty of Law of Vrije Universiteit in the Proceedings of International Seminar on Mental Health Legislation, Amsterdam (October 1988) and The Changing Face of Mental Health Legislation in Japan, which was the keynote address for the 9th annual Congress of the Australian and New Zealand Association of Psychiatry, Psychology and a joint Congress of the American Academy of Psychiatry and the Law, Melbourne, Australia (October 1988) and published by the International Commission of Jurists in the Review No. 42 (June 1989).

\section{References}

Fukazawa, S. (1964) Narayamabushi-ko. Tokyo: Shincho-sha.

Harding, T., Schneider, J., Visotsky, H. \& Graves, C. (1986) Human Rights and Mental Patients in Japan. Geneva: International Commission of Jurists, pp. 5-6.

The International Commision of Jurists (1984) The mentally ill in Japan. The ICJ Review, 32, 15-20.

KaNEKo, J. (1973) Nihon igaku-shi nenpyou. Tokyo: NihonSeishinbyouin-Kyoukai, pp. 156,332,336-341.

THE LANCET (1982) Japan: Human rights of mentally ill offenders. The Lancet, i, 673.

ToTsUKA, E. (1985) Ningensei kaihuku eno michi. In Seishin-iryo to jinken (3) Ningensei kaihuku eno michi (eds. E. Totsuka and I. Hirota). Tokyo: Aki-shobo, pp. 199-240.

\title{
The use of adult psychiatric day care facilities in Worcester
}

\author{
Margaret Du FeU, Senior Registrar in Psychiatry, All Saints Hospital, \\ Birmingham B18 5SD
}

The 1975 White Paper Better Services for the Mentally Ill recognises different roles for day hospitals, day centres and the voluntary sector in the provision of psychiatric day care. Two broad client groups, needing short-term support or long-term care, are described. However, Vaughn (1983 and 1985) and Wilkinson (1984) have reviewed lack of co-ordinated planning in the provision of services and the place- ment of clients. Carter (1981) in a major survey of day care, showed that in many cases it was difficult to differentiate between day hospital and day centre services or client groups.

Worcester provides a unique opportunity for the study of day care use. The Worcester Development Project was set up as a local pattern of psychiatric services with funding from the DHSS in order to test 
and evaluate the kind of service envisaged in the 1975 White Paper. The project has an Acute Psychiatric Day Hospital at the Newtown branch of Worcester Royal Infirmary, the Studdert-Kennedy Social Services day centre, and the MIND day centre run by the mental health charity. Each of these facilities is used by clients on a full or part-time basis. The Day Hospital has 20 places a day, Studdert-Kennedy has 40 and MIND has open access. The statutory facilities are open five days a week. MIND is open three mornings a week plus bank holidays. The hypothesis the survey intended to test was that there is no difference between the client groups attending these three facilities in terms of demographic details, psychiatric diagnosis, route of referral and length of stay.

\section{The study}

A census of clients and patients using the day care facilities was undertaken during the week of 19-23 September 1988. Consent for this was obtained from patients and staff at the Day Hospital and from clients and staff at the Studdert-Kennedy day centre and the MIND day centre. Ethical Committee approval was obtained. The census was conducted by collecting anonymous information on clients and patients who attended with regard to age, sex, marital status, presumed diagnosis and length of stay. Further information was requested in the form of an anonymous questionnaire. This was given to the client with appropriate explanations of the reasons for the survey and assurance of confidentiality. Help was given in completing the questionnaire if this was requested.

\section{Findings}

In the week of the survey, 33 patients attended the Newtown Day Hospital (DH), 41 clients attended the Studdert-Kennedy Day Centre (SKDC) and 38 clients attended MIND. At the DH $100 \%$ of questionnaires were completed but only $34 \%$ were returned from SKDC and 39\% from MIND, though basic data were available on all attenders.

Age

Complete data were obtained. There were only 12 attenders under 30 ; one $(3 \%)$ at the $\mathrm{DH}$, six $(15 \%)$ at SKDC and five (13\%) at MIND.

Fifty-eight attenders were over $50 ; 17(52 \%)$ at the DH, $16(39 \%)$ at SKDC and $25(66 \%)$ at MIND. By the $\chi^{2}$ test, there was no significant difference in age distribution between the DH and MIND or the DH and SKDC, but the clients at MIND were significantly older than those at SKDC $\left(\chi^{2}=6.78\right.$ $[P<0.01])$.

\section{Sex}

There was no significant difference between the three facilities; between a half and two-thirds of attenders at all three facilities were female.

\section{Marital status}

Complete information was available from the $\mathrm{DH}$ and SKDC. For MIND attenders data were only available from the $39 \%$ of questionnaires completed. At the $\mathrm{DH}, 13$ people (40\%) were single, eight (24\%) married, and $12(36 \%)$ widowed, separated or divorced. At the SKDC, $18(44 \%)$ were single, ten $(24 \%)$ married and $13(32 \%)$ widowed, separated or divorced. At MIND the (incomplete) figures were ten $(66 \%)$ single, two (13\%) married and three $(20 \%)$ widowed, separated or divorced. Men were more likely to be single (about $67 \%$ at all three centres). Of female MIND attenders, $67 \%$ were also single.

\section{Diagnosis}

Complete data on diagnosis were available from questionnaires at the $\mathrm{DH}$ and anonymous information at SKDC. At MIND anonymous estimates of diagnostic categories were given by helpers and therefore the information was less reliable. A diagnosis of schizophrenia was given for $16(48 \%)$ of DH attenders, ten (24\%) SKDC clients and $11(29 \%)$ MIND clients. Manic depressive psychosis was the diagnosis for five patients at the $\mathrm{DH}$ and four at SKDC. Twenty-two people at MIND were thought to be anxious or depressed.

Other diagnoses were phobias, alcohol abuse, social skills, personality and sexual problems. One client, who attended both SKDC and MIND, was mentally handicapped.

\section{Length of attendance}

Information was complete from attendance records with the exception of one female client at SKDC. Figures for those staying for over one year were for the DH seven patients (21\%), SKDC 26 clients (65\%), and MIND 30 clients (79\%). Analysis using $\chi^{2}$ showed that there was no significant difference in the proportion of people attending over a year between SKDC and MIND $\left(\chi^{2}=1.25\right)$, but that a significantly smaller proportion attended the $\mathrm{DH}$ for over a year (DH compared with SKDC: $\chi^{2}=12.28$ $[P<0.001])\left(\mathrm{DH}\right.$ compared with MIND: $\chi^{2}=19.19$ $[P<0.001])$.

Of people attending for over a year, four $(57 \%)$ of those at the DH had a diagnosis of schizophrenia, while five $(19 \%)$ at SKDC were schizophrenic $(P=$ 0.06 Fisher Exact Test). In addition, questionnaire results from the DH showed that 11 of the 26 patients there who had attended for less than one year had attended in the past. 
The following data for physical illness, accommodation and source of referral were obtained from questionnaires, and were therefore incomplete from SKDC (34\%) and MIND (39\%).

\section{Physical illness}

Various physical illnesses, including epilepsy, diabetes, deafness and hypertension, were reported by attenders at the DH (33\%), SKDC (15\%) and MIND (40\%).

\section{Accommodation}

Information from questionnaires showed that $60 \%$ of responders from MIND lived alone, as did $29 \%$ from SKDC and $39 \%$ of DH attenders.

\section{Source of referral}

Referrals came from psychiatrists, psychologists, social workers, community psychiatric nurses and general practitioners. At MIND and SKDC there were informal and self referrals.

About a third of referrals to MIND and SKDC came from psychiatrists, while $85 \%$ of those to the DH came from psychiatrists, the remainder coming from community nurses and one each from a psychologist and a social worker.

\section{Comment}

There were some practical difficulties in the performance of the census. Because an attempt was made to obtain comparable information from each of the three client groups, the questionnaire was formulated to be suitable for completion in a relatively informal way, and at the Day Hospital the patients' notes were not used. However, because of the more formal setting of the Day Hospital and because the clients there were in the patient role, every attender did complete a questionnaire with appropriate help from the staff and reliable information was obtained. At the other two centres there was a smaller proportion of completed questionnaires despite the help of the staff and the interest of many of the clients. There were also time constraints and more fears about lack of confidentiality outside the hospital.
Only attenders during the week of the census were counted but some of the attendances were quite brief. In all three centres there were people attending for short specific sessions. It was decided to include all of these. The anticipated problem of client overlap was confined to three clients, who were counted at each place they attended.

Because of limited numbers and incomplete information, it was only possible to disprove the hypothesis that the client groups attending the three day facilities were the same in a few respects. Significant differences in age and length of stay were found. Some trends were shown without reaching statistical significance. The two clear groups of attenders described in Better Services for the Mentally Ill were not found, although the MIND centre clients showed more features of the chronic attenders than the Studdert-Kennedy Day Centre group. The Day Hospital tended to concentrate on shorter periods of therapy, but had some chronic and recurrent patients, mainly with schizophrenia. The different sources of referral to the three facilities show that the clients' attendance patterns are not due to careful planning by psychiatrists, who tend to concentrate their referrals on the Day Hospital.

The study has disproved the hypothesis that client groups attending the Day Hospital, Social Services and voluntary sector day facilities in Worcester do not differ from each other. Differences in these groups are demonstrated but further research would be needed to show whether these differences show that each type of day care is being used appropriately.

\section{References}

CARTER, J. (1981) Day Services for Adults: Somewhere to Go. National Institute Social Services Library No. 4. London: George Allen \& Unwin.

Department of Health aNd SOCIal SeCURITy (1975) Better Services for the Mentally Ill. (Cmnd 6233). London: HMSO.

VAUGHN, P. J. (1983) The disordered development of day care in psychiatry. Health Trends, 15, 91-94.

(1985) Developments in psychiatric day care. British Journal of Psychiatry, 147, $1-4$.

Wilkinson, G. (1984) Day care for patients with psychiatric disorders. British Medical Journal, 288, 1710-1711. 